\title{
Regional and local land subsidence at the Venice coastland by TerraSAR-X PSI
}

\author{
L. Tosi ${ }^{1}$, T. Strozzi ${ }^{2}$, C. Da Lio ${ }^{1}$, and P. Teatini ${ }^{1,3}$ \\ ${ }^{1}$ Institute of Marine Sciences, National Research Council, Venice, Italy \\ ${ }^{2}$ GAMMA Remote Sensing, Gümligen, Switzerland \\ ${ }^{3}$ Dept. of Civil, Architectural and Environmental Engineering, University of Padova, Italy \\ Correspondence to: L. Tosi (luigi.tosi@ ismar.cnr.it) \\ Published: 12 November 2015
}

\begin{abstract}
Land subsidence occurred at the Venice coastland over the 2008-2011 period has been investigated by Persistent Scatterer Interferometry (PSI) using a stack of 90 TerraSAR-X stripmap images with a $3 \mathrm{~m}$ resolution and a 11-day revisiting time. The regular X-band SAR acquisitions over more than three years coupled with the very-high image resolution has significantly improved the monitoring of ground displacements at regional and local scales, e.g., the entire lagoon, especially the historical palaces, the MoSE large structures under construction at the lagoon inlets to disconnect the lagoon from the Adriatic Sea during high tides, and single small structures scattered within the lagoon environments. Our results show that subsidence is characterized by a certain variability at the regional scale with superimposed important local displacements. The movements range from a gentle uplift to subsidence rates of up to $35 \mathrm{~mm} \mathrm{yr}^{-1}$. For instance, settlements of $30-35 \mathrm{~mm} \mathrm{yr}^{-1}$ have been detected at the three lagoon inlets in correspondence of the MoSE works, and local sinking bowls up to $10 \mathrm{~mm} \mathrm{yr}^{-1}$ connected with the construction of new large buildings or restoration works have been measured in the Venice and Chioggia historical centers. Focusing on the city of Venice, the mean subsidence of $1.1 \pm 1.0 \mathrm{~mm} \mathrm{yr}^{-1}$ confirms the general stability of the historical center.
\end{abstract}

\section{Introduction}

Cities in lowlying coastlands and deltaic regions are the sites most susceptible to land subsidence worldwide. The influence of land subsidence on these communities and environments can be very significant, increasing vulnerability to saltwater intrusion and flooding, threatening agriculture and ecological systems. Presently, land subsidence caused mainly by extraction of groundwater is threatening Jakarta $(\mathrm{Ng}$ et al., 2012), Ho Chi Minh City (Erban et al., 2014), Bangkok (Phien-wej et al., 2006), Shanghai (Dong et al., 2014), i.e. rapidly expanding urban areas which require huge amounts of water for domestic and industrial water supply.

Similarly to that occurring in these urban centres in developing countries, Venice experienced anthropogenic land subsidence due to aquifer overexploitation in the past (Carbognin et al., 2004). Although the effect of groundwater pumping ended a few decades ago, a reliable and detailed knowledge of land subsidence affecting the historical center is even more important today as vulnerability has continuously increased over the years. The city of Venice and its surrounding lagoon is presently one of the sites most sensitive to land subsidence worldwide. Even a few $\mathrm{mm} \mathrm{yr}^{-1}$ loss of elevation with respect to the mean sea level can threaten the city's survival and irrevocably change the natural environment of the lagoon.

This is the reason why monitoring land subsidence in the Venice area at a very high accuracy has always been important. Recent studies have highlighted a significant heterogeneity of the subsidence at the local scale, both connected to the subsoil characteristics and human interventions (Strozzi et al., 2009; Tosi et al., 2012, 2013). Thus, in addition to the millimetric accuracy, a metric spatial resolution is also required for improving the understanding of the natural and human-induced components.

In this study, we use a long-term stack of TerraSAR-X scenes processed by PSI (Persistent Scatterer Interferome- 

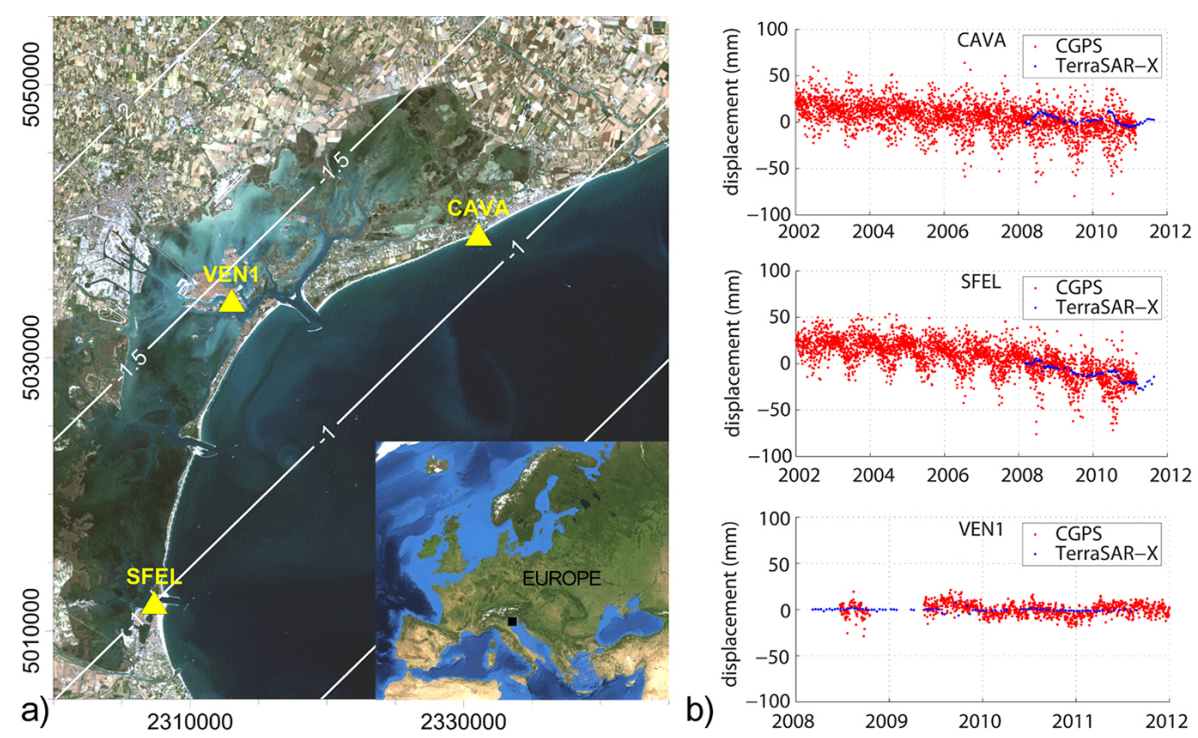

Figure 1. (a) Data calibration: plane model based on the Venice (VEN1), Chioggia (SFEL), and Cavallino (CAVA) CGPS displacements, used to correct the PSI outcome. (b) Comparison between the CGPS and the calibrated PS time series.

try) to monitor land subsidence at the Venice coastland from 2008 to 2011 and highlight the local movements of historical palaces and monuments in the Venice center, single small structures scattered within the natural lagoon environments, and the MoSE large structures under construction at the lagoon inlets.

\section{Methods}

The Interferometric Point Target Analysis (IPTA; Werner et al., 2003; Wegmüller et al., 2004; Teatini et al., 2005), a PSI implementation chain, is applied on a stack of 90 TerraSAR$\mathrm{X}$ stripmap images for the period 2008 to 2011 with a regular 11-day revisiting time. In order to correct the so-called flattening problem, i.e. the slight phase tilt resulting by the inaccuracy in estimation of the orbital baseline due to the imperfect knowledge of the satellite positions (Teatini et al., 2012a, b), IPTA results have been calibrated using three permanent GPS stations (CGPS) well distributed in the monitored area, i.e. VEN1 at Venice, CAVA on the northern Cavallino littoral strip, and SFEL in the nearby of Chioggia at the southern tip of the lagoon (Fig. 1a). Figure 1a shows the tilting plane used to calibrate the PSI solution on the CGPS records. Even if the slope is relatively small, the corrections between 1 to $2 \mathrm{~mm} \mathrm{yr}^{-1}$ are significant for the Venice coastal area. Figure $1 \mathrm{~b}$ points out the satisfactory match between the CGPS time series and the average time series of the persistent scatterers (PS) in the surrounding of the GPS stations once calibrated the PSI solution.

IPTA provides land displacements along the line-of-sight (LOS) between the satellite and the targets. Due to the small incidence angle of the radar signal, IPTA measurements are less sensitive to the horizontal components of the displacement than to the vertical one. Nevertheless, the occurrence of differential horizontal displacements, for example because of the tectonics, would affect the SAR interferometry measurement. The network of the CGPS stations shows however that the Venice coastland is uniformly moving north-eastward (Teatini et al., 2005; Tosi et al., 2010). Therefore, the differential component of the horizontal displacement rate perpendicular to the TerraSAR-X inclination orbit is smaller than $1 \mathrm{~mm} \mathrm{yr}^{-1}$, and negligible with respect to the vertical displacement rate. In our results the difference between the LOS and the vertical components of the movement (about $15 \%$ for TerraSAR-X, i.e. less than $1 \mathrm{~mm} \mathrm{yr}^{-1}$ for the large majority of the PS) is neglected.

\section{Results}

\subsection{Land subsidence at the regional scale}

Figure 2a shows the PSI solution in terms of average displacement rates on the whole coastal area of Venice. An impressive number of $1933690 \mathrm{PS}$, i.e. $2275 \mathrm{~km}^{-2}$, has been detected. The movement velocity ranges from a gentle uplift $\left(\sim 2 \mathrm{~mm} \mathrm{yr}^{-1}\right.$ ) to large subsidence (up to $30 \mathrm{~mm} \mathrm{yr}^{-1}$ ).

Similarly to previous results obtained with ENVISAT images (e.g., Teatini et al., 2012a, b), the monitoring outcome reveals that this portion of the Northern Adriatic coastland is characterized by a certain variability in terms of land subsidence at the large (or regional) scale. A number of zones with different features in the displacement rates is distinguished:

- the north-western zone (A circle in Fig. 2a): this area is characterized by uniform stability. The average sub- 

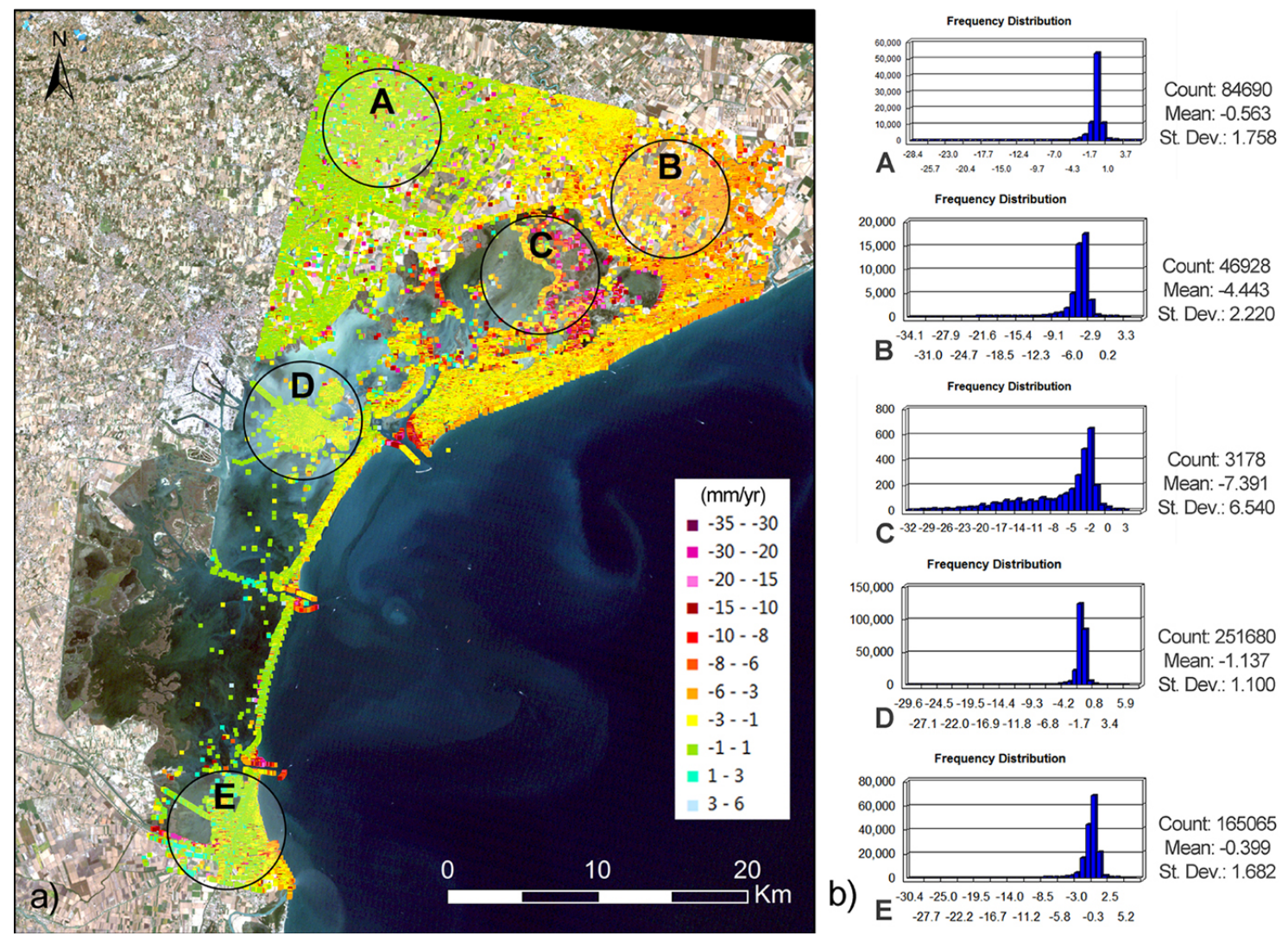

Figure 2. (a) Average land displacements $\left(\mathrm{mm} \mathrm{yr}^{-1}\right)$ for the Venice coastland obtained by PSI on TerraSAR-X images acquired between March 2008 and August 2011. Positive values mean uplift, negative values land subsidence. A Landsat image obtained from the US Geological Survey - Earth Resources Observation and Science (EROS) Center is used as base map. (b) Frequency distribution of the displacement rates for the PS located in the A-E circular areas $(r=3 \mathrm{~km})$ highlighted on the map.
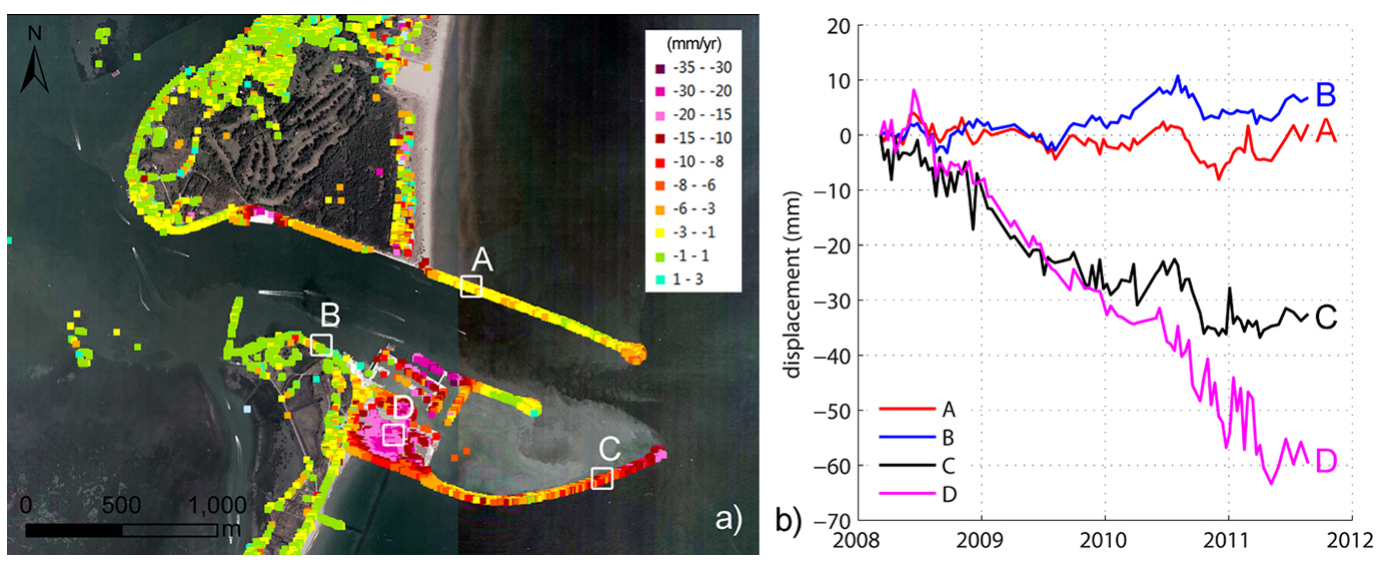

Figure 3. (a) Mean displacement rates between March 2008 and August 2011 from TerraSAR-X interferometry at Malamocco inlet. The image background is an aerophotograph acquired in 2007. Negative values indicate settlement, positive mean uplift. (b) Displacement history in the satellite line-of-sight direction for four scatterers (A, B, C, D). See location 1a in Fig. 1.

sidence $\eta_{r}$ is less than $1 \mathrm{~mm} \mathrm{yr}^{-1}$ and the standard deviation $\sigma_{\eta}$ is about $1-2 \mathrm{~mm} \mathrm{yr}^{-1}$ (Fig. 2b). Only local bowls of relatively large displacements caused by hu- man activities (groundwater pumping, development of new urban and industrial zones) are detected;

- the north-eastern zone (B circle in Fig. 2a): a relatively uniform $\left(\sigma_{\eta} \approx 2 \mathrm{~mm} \mathrm{yr}^{-1}\right)$ land subsidence on the order 

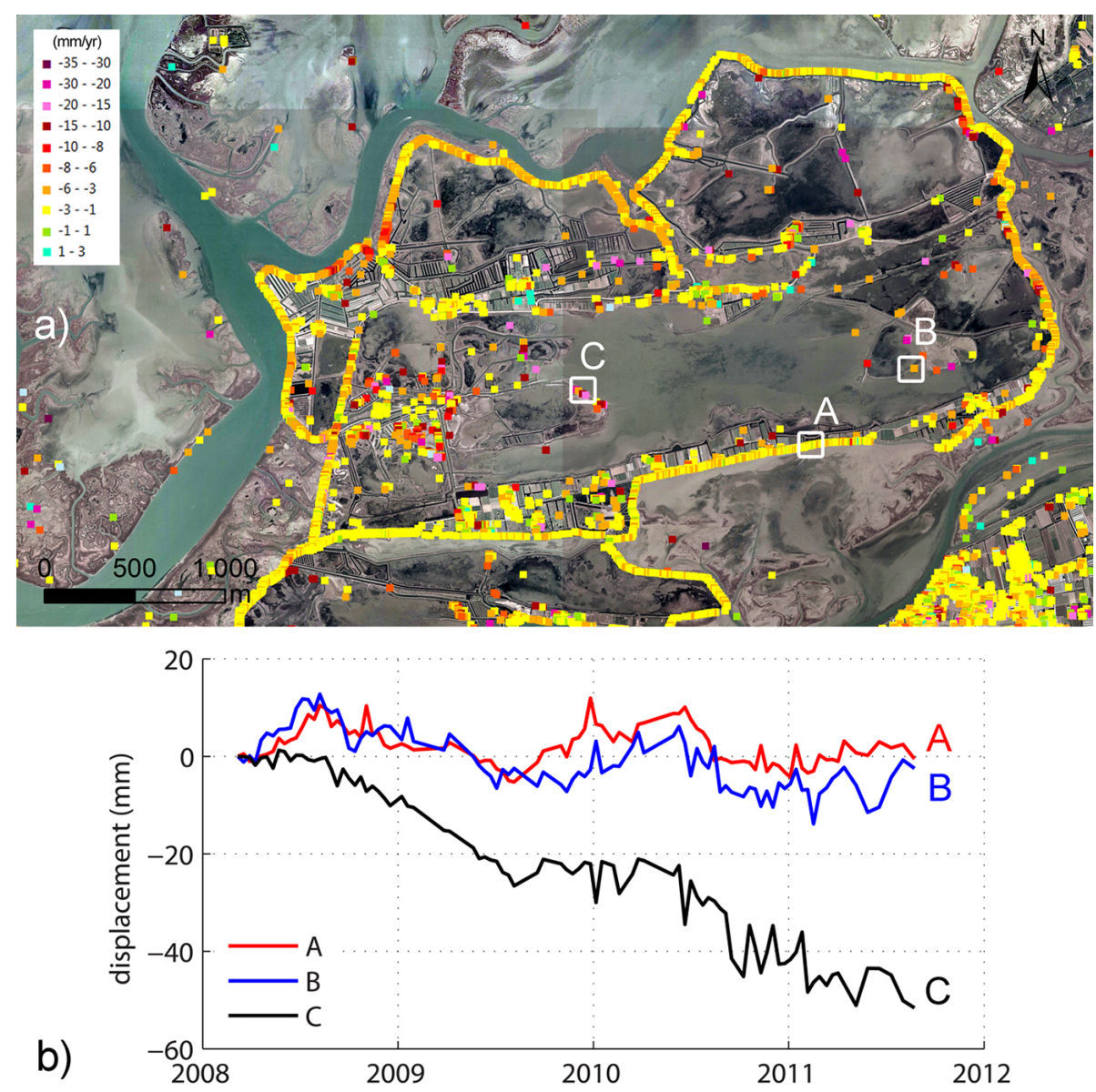

Figure 4. (a) Mean displacement rates between March 2008 and August 2011 from TerraSAR-X interferometry at Valle Paleazza, Northern Venice lagoon. The image background is an aerophotograph acquired in 2007. Negative values indicate settlement, positive mean uplift. (b) Displacement history in the satellite line-of-sight direction for three scatterers (A, B, C). See location 2 a in Fig. 1.

of $4-6 \mathrm{~mm} \mathrm{yr}^{-1}$ is threatening this part of the coastal area. Land subsidence due to aquifer exploitation occurs mainly along coastal sector; also processes related to the recent land reclamation (the zone was reclaimed between 1900 and 1930) likely contribute to the total movements;

- the northern lagoon ( $\mathrm{C}$ circle in Fig. 2a): it is the zone characterized by the highest variability $\left(\sigma_{\eta} \approx 6 \mathrm{~mm} \mathrm{yr}^{-1}\right)$ with land displacements ranging between -1 and $-30 \mathrm{~mm} \mathrm{yr}^{-1}$. The largely heterogeneous nature of the shallow Holocene deposits strongly impacts the movements;

- Venice and the central lagoon (D circle in Fig. 2a): the historical centre and the surrounding lagoon is relatively stable. On the average $\eta_{r}=1 \mathrm{~mm} \mathrm{yr}^{-1}$, with a very narrow $\mathrm{v}$ ariability of $\sigma_{\eta} \approx 1 \mathrm{~mm} \mathrm{yr}^{-1}$. The Holocene deposits are relatively thin (about $5 \mathrm{~m}$ ) and groundwater withdrawals have been precluded since the early 1970s;
- Chioggia and the southern coastland (E circle in Fig. 2a): moving to the south, land subsidence remains generally small. The city of Chioggia is stable $\left(\sigma_{\eta},<1 \mathrm{~mm} \mathrm{yr}^{-1}\right)$, and a certain subsidence occurs mainly along the coastline in the soundings of the mouths of the main rivers (the Brenta and Adige rivers).

\subsection{Ground displacements at the local scale}

A significant local scale variability of the land displacements is superposed on the regional trend of land subsidence. In the following, a few cases showing the typical local movements observed along the Venice coast are presented and discussed.

\subsubsection{The MoSE constructions at the lagoon inlets}

Starting from the middle 1990s, the jetties at the three inlets were reinforced, and since 2005, in the framework of the MoSE works (i.e. the project of mobile barriers for the temporarily closure of the lagoon to the sea), they have been strongly reshaped and supplemented by offshore breakwa- 

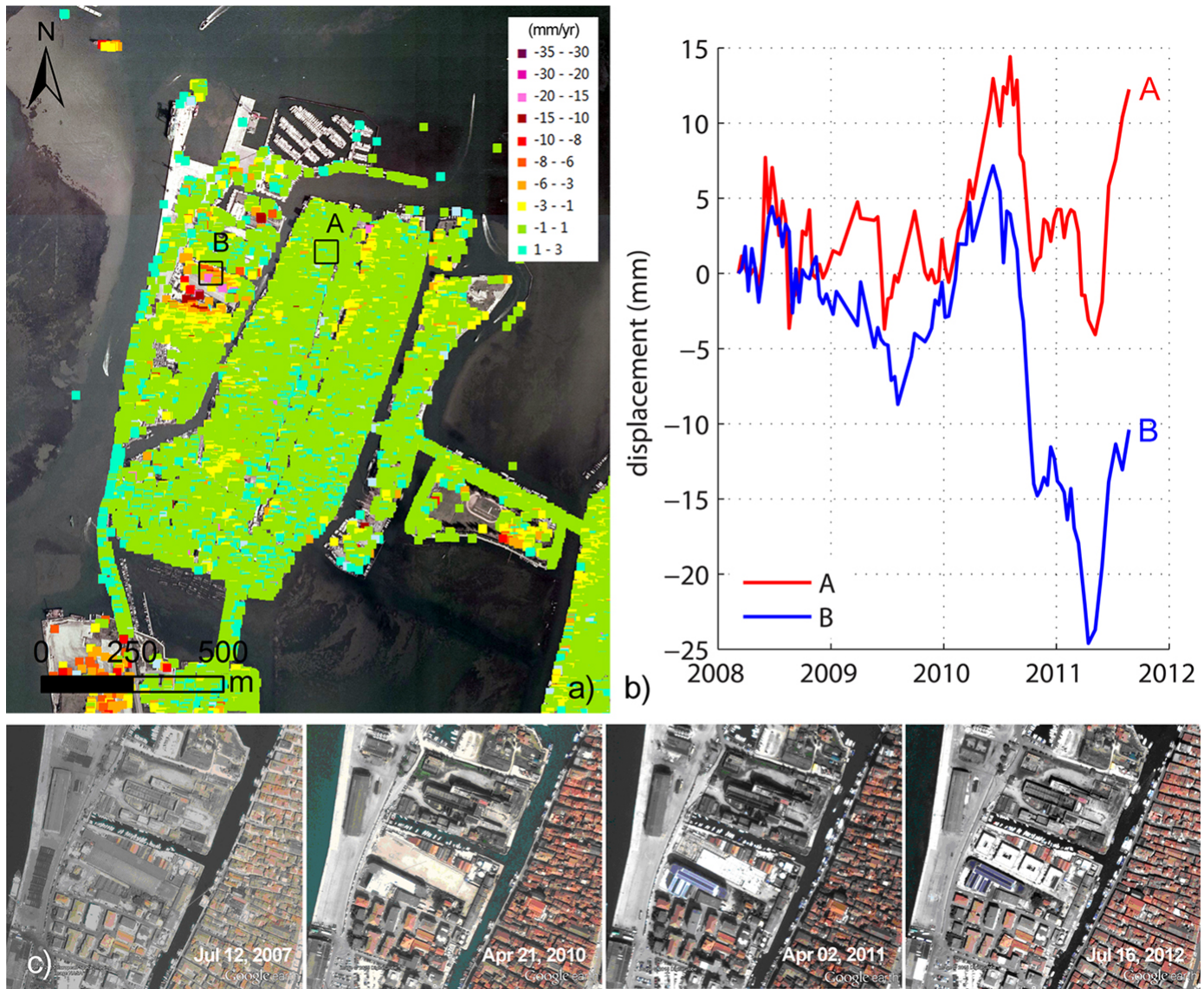

Figure 5. (a) Mean displacement rates between March 2008 and August 2011 from TerraSAR-X interferometry at Chioggia. The image background is an aerophotograph acquired in 2007. Negative values indicate settlement, positive mean uplift. (b) Displacement history in the satellite line-of-sight direction for two scatterers (A, B). (c) Satellite Google Earth images showing the building construction carried out at location B from 2010, cause of the large consolidation highlighted by PSI measurements in the zone from mid-2010 (Google Earth, data source: European Space Imaging, Image NASA; Digital Globe, Image). See location 3a in Fig. 1.

ters. Presently the works at the inlets are still ongoing and monitoring land displacements in these sectors, has a double aim, namely (i) the evaluation of possible effects of the works on the littoral environment, and (ii) the quantification of the consolidation of the new coastal structures. The former issue can support the public authorities in monitoring the environmental impacts of these giant works, the latter can help the engineering companies building the MoSE to check the absolute and differential displacements that can threaten the integrity and efficiency of the structures.

Figure 3a shows a large variability of the displacement velocities characterizing the different degree of the consolidation of the structures at the Malamocco inlet. Sinking rates less than $3 \mathrm{~mm} \mathrm{yr}^{-1}$ characterize the parts of the jetties where older restoration works were carried out (A, B), while sinking rates up to $30 \mathrm{~mm} \mathrm{yr}^{-1}$ are measured in the newer structures mainly built in the southern side $(C, D)$. Figure $3 \mathrm{~b}$ shows the displacement history of four scatterers selected in correspondence of old restoration works and new structures. The scatterers A and B highlight the ground stability after the old restoration in these parts of the inlets. The scatterer $\mathrm{C}$, located in the new structure of the outer jetty, sinks about $20 \mathrm{~mm} \mathrm{yr}^{-1}$ in the whole monitored period, the lower values detected after 2010 show that the primary consolidation has likely been completed. Instead scatterer D, in the newest portion of the lock, is still experiencing primary consolidation due to the new load, with velocity rates of up to $30 \mathrm{~mm} \mathrm{yr}^{-1}$. Notice that the works at the inlet generally do not affect the land subsidence in the littoral surroundings.

\subsubsection{The natural marshlands and the fish farms}

Monitoring of land subsidence in natural marshlands and fish farms is a major challenge. The use of traditional methodologies (levelling, GPS) are impractical in these environment. SAR- based methodologies represent a unique approach in this context. Specifically, the X-band acquisitions, which are characterized by a higher resolution with respect to the $\mathrm{C}$ band scenes, have demonstrated a high effectiveness. Figure 4 shows the impressive capability of IPTA to detect 


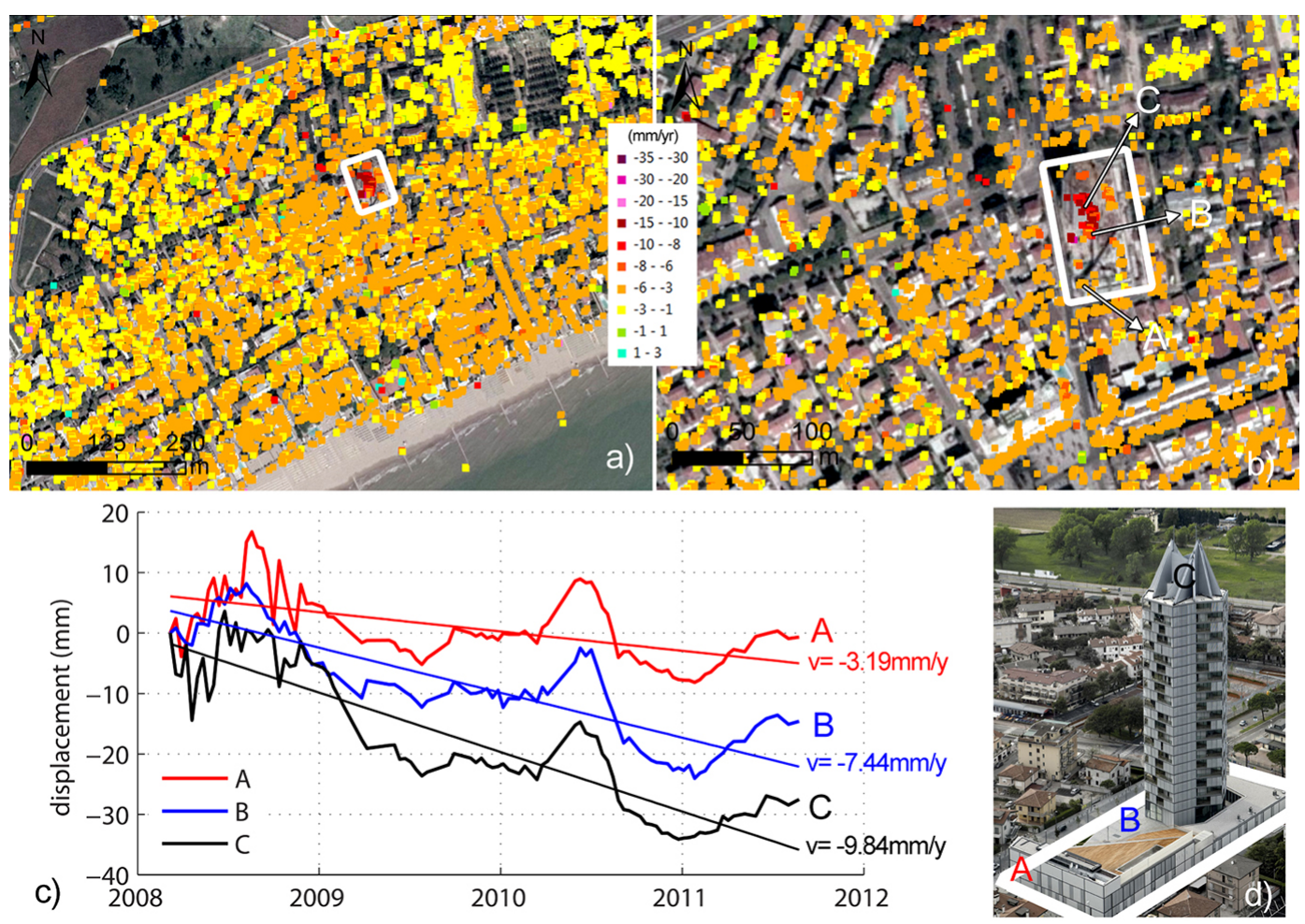

Figure 6. (a, b) Mean displacement rates between March 2008 and August 2011 from TerraSAR-X interferometry at Jesolo. The image background is an aerophotograph acquired in 2007. Negative values indicate settlement, positive mean uplift. (c) Displacement history in the satellite line-of-sight direction for three scatterers (A, B, C). (d) Photograph of Aquileia Tower, Jesolo, which is the cause of the largest movements. See location 4a in Fig. 1.

the displacements of thousands of radar targets in the Valle Paleazza, a fish farm in the northern Venice lagoon. The majority of the PS are located on artificial embankments bounding these lagoon zones whose water level is artificially managed, but several radar reflectors are also located within the fish farm and also on the natural marshland located to the west. The displacement rates are extremely variable, with the largest subsidence usually detected in the inner zones while the fish farm embankments, built up in the previous centuries, are more stable.

\subsubsection{The lagoon and coastal urban areas}

Apart from Venice, which has been the focus of several studies on land subsidence most recently (Tosi et al., 2013), other important cities and tourist villages are located in the area. Two main tourist centres are Chioggia and Jesolo at the southern and northern tip of the Venice lagoon, respectively.

The subsidence maps detected by PSI for these two cities are provided in Figs. 5 and 6, respectively. Chioggia is almost stable and Jesolo subsides at an average rate equal to $3 \mathrm{~mm} \mathrm{yr}^{-1}$. However, local bowls of large subsidence, up to $10 \mathrm{~mm} \mathrm{yr}^{-1}$, have been detected in both urban areas. Detailed investigations point out that these occurrences are usually connected with the construction of new large buildings that exert new heavy loads on the land surface, leading to consolidation of the shallow subsoil below the foundations.

\section{Conclusions}

PSI on a large stack of stripmap TerraSAR-X images from 2008 to 2011 has proven particularly effective for monitoring land subsidence in the Venice coastland. The interferometric processing of this dataset allows for the characterization of the land movements at both the regional and local scales. The sufficiently large area covered by the images allows the use of a few CGPS stations to calibrate the radar solution. The high resolution and acquisition frequency guarantees the possibility of accurately detecting local-scale short-time anomalies in the subsidence pattern. Our results clearly show the large variability characterizing the consolidation of the structures at the inlets; hence, the effect of the primary consolidation is clearly visible close to the construction of new buildings due to the ongoing urbanization of the coastline. Venice is still experiencing natural land subsidence with rates in the range $1.1 \pm 1.0 \mathrm{~mm} \mathrm{yr}^{-1}$, mainly because of the heterogeneous nature and age of the lagoon subsoil.

TerraSAR-X acquisitions over the Venice coastland continued at a regular interval of 11 days after August 2011. We 
plan to update the PSI analysis using 49 new images acquired through November 2013. In the newest PSI analysis particular attention will be given to short observation periods, the occurrence of appearing and disappearing scatterers, and to the thermal dilation component of displacement (Monserrat et al., 2011) for a better characterization of the behaviour of large structures.

Acknowledgements. This work has been developed in the framework of the Action 2 (SP3-WP1) funded by the Flagship Project RITMARE - The Italian Research for the Sea - coordinated by the Italian National Research Council and funded by the Italian Ministry of Education, University and Research within the National Research Program 2011-2013. Data courtesy: (1) TerraSAR$\mathrm{X}$, Project COA0612 ${ }^{\odot}$ DLR “Assessing vertical movements of natural tidal landforms and anthropogenic structures at the Venice Lagoon inlets" and (2) CAVA and SFEL CGPS time series, Magistrato alle Acque (Venice Water Authority) through its concessionary Consorzio Venezia Nuova, and (3) VEN1 time series, Nevada Geodetic Laboratory (NGL), obtained from http://geodesy.unr.edu/.

\section{References}

Carbognin, L., Teatini, P., and Tosi, L.: Relative land subsidence in the lagoon of Venice, Italy, at the beginning of the new millennium, J. Mar. Sys., 51, 345-353, 2004.

Dong, S., Samsonov, S., Yin, H., and Ye, S.: Time-series analysis of subsidence associated with rapid urbanization in Shanghai, China measured with SBAS InSAR method, Environ. Earth Sci., 72, 677-691, 2014.

Erban, L. E., Gorelick, S. M., and Zebker, H. A.: Groundwater extraction, land subsidence, and sea-level rise in the Mekong Delta, Vietnam, Environ. Res. Lett., 9, 084010, doi:10.1088/17489326/9/8/084010, 2014.

Monserrat, O., Crosetto, M., Cuevas, M., and Crippa, B.: The Thermal Expansion Component of Persistent Scatterer Interferometry Observations, Geosci. Remote Sens. Lett., 8, 864-868, doi:10.1109/LGRS.2011.2119463, 2011.

Ng, A. H.-M., Ge, L., Li, X., Abidin, H. Z., Andreas, H., and K. Zhang: Mapping land subsidence in Jakarta, Indonesia using persistent scatterer interferometry (PSI) technique with ALOS PALSAR, Int. J. Appl. Earth Obs., 18, 232-242. 2012.

Phien-wej, N., Giao, P. H., and Nutalaya, P.: Land subsidence in Bangkok, Thailand, Eng. Geol., 82, 187-201, 2006.

Strozzi, T., Teatini, P., and Tosi, L.: TerraSAR-X reveals the impact of the mobile barrier works on Venice coastland stability, Remote Sens. Environ., 113, 2682-2688, 2009.

Teatini, P., Tosi, L., Strozzi, T., Carbognin, L., Wegmüller, U., and Rizzetto, F.: Mapping regional land displacements in the Venice coastland by an integrated monitoring system, Remote Sens. Environ., 98, 403-413, 2005.
Teatini, P., Tosi, L., Strozzi, T., Carbognin, L., Cecconi, G., Rosselli, R., and Libardo, S.: Resolving land subsidence within the Venice Lagoon by persistent scatterer SAR interferometry, Phys. Chem. Earth. Pt. A/B/C, 40, 72-79, 2012a.

Teatini, P., Tosi, L., and Strozzi, T.: Comment on "Recent subsidence of the Venice Lagoon from continuous GPS and interferometric synthetic aperture radar" by Y. Bock, S. Wdowinski, A. Ferretti, F. Novali, and A. Fumagalli., Geochem. Geophys. Geosys. 13, Q07008, doi:10.1029/2012GC004191, 2012b.

Tosi, L., Teatini, P., Strozzi, T., Carbognin, L., Brancolini, G., and Rizzetto, F.: Ground surface dynamics in the northern Adriatic coastland over the last two decades, Rend. Fis. Acc. Lincei, 21, S115-S129, 2010.

Tosi, L., Teatini, P., Bincoletto, L., Simonini, P., and Strozzi, T.: Integrating geotechnical and interferometric SAR measurements for secondary compressibility characterization of coastal soils, Surv. Geophys., 33, 907-926, 2012.

Tosi, L., Teatini, P., and Strozzi, T.: Natural versus anthropogenic subsidence of Venice, Nat. Sci. Reports, 3, 2710, doi:10.1038/srep02710, 2013.

Wegmüller, U., Werner, C., Strozzi, T., and Wiesmann, A.: Multitemporal interferometric point target analysis, Ser. Remote Sens., 3, 136-144, 2004.

Werner, C., Wegmüller, U., Strozzi, T., and Wiesmann, A.: Interferometric Point Target Analysis for deformation mapping. Proc. of the Geoscience and Remote Sensing Symposium (IGARSS 2003), IEEE International, 7, 4362-4364, 2003. 